\title{
«La Tremenda Corte»: un caso de lingüisticidio
}

\section{Blanca Estela Ruiz}

Algo está pasando con la lengua: parece fija y sin embargo... ise mueve!, habría dicho Galileo si en vez de astrónomo hubiese sido lingüista. Pero al decir "lengua" no nos referimos al homónimo músculo encerrado en los arcos dentarios que pasa de una danza a otra entre el gustar, succionar, masticar y deglutir los alimentos, y emitir sonidos o articular palabras. Tampoco se trata del manjar en salsa verde que suele brincar con el pinchazo de un inexperto tenedor. Algo está pasando con la lengua, con ese conjunto de signos orales organizados en un sistema gramatical que, de hablantes en hablantes, se agita, como el colibrí, en su aparente quietud.

De lengua en lengua se rumora que la polisemia —responsable de la manipulación lúdica y de la ligereza de lengua - ha aniquilado la mecanicidad lingüística, le ha sacado la lengua a la Real Academia Española y esta no ha tenido más remedio que morderse la suya.

¿Pero cómo, cuándo, dónde sucedió este hecho y quién está implicado en este lingüisticidio? Repiquetea la campanilla y una voz anuncia: "¡Audiencia pública. El tremendo juez de La Tremenda Corte, va a resolver un tremendo caso!" Tres martillazos y empieza el juicio.

\section{1. ¿Quién acusa?}

La lengua, como sistema eminentemente social, está en constante evolución, se mueve, y para su análisis, el lingüista ginebrino Ferdinand de Saussure distinguió entre diacronía, o estudio de los 
cambios lingüísticos a través del tiempo, y sincronía, o la constitución y el funcionamiento de la lengua en un momento determinado. En esta última dimensión se ubica la gramática: "quien dice gramatical, dice sincrónico y significativo"' .

Durante mucho tiempo se concibió la gramática como "el arte de hablar y escribir correctamente" conforme con los modelos clásicos. Pero, ¿qué es hablar o escribir "correctamente"? ¿Las nomenclaturas acuñadas por la Real Academia de la Lengua, organismo que, al decir del escritor jalisciense Dante Medina, jugando con los homónimos, "cada vez es más difícil creer que sea real dado lo ficticio de sus afirmaciones"?

En la antigüedad se pretendió normar y regular los usos orales de acuerdo con los parámetros establecidos en los textos literarios. El normatismo desconoce que las lenguas sufren cambios y se influyen recíprocamente, pues si alguna forma lingüística se generaliza, se acepta y se integra al léxico bajo el principio Vox populi, vox Dei. Así, por ejemplo, el español ha recibido préstamos del árabe, del francés, del inglés y del náhuatl, entre otras lenguas, para incluir en su diccionario palabras como "azúcar", "chofer", "club" y "chocolate". Si bien, la función primordial del español —como de todas las lenguases la comunicación (de allí la importancia de mantener su identidad lingüística), junto a este está latente el argot, jerga, caló, germanía o cualquier variante dialectal que dentro de una misma lengua producen ciertos grupos lingüísticos ${ }^{3}$. Por citar sólo unos, mencionaremos el lunfardo de algunos estratos sociales de Buenos Aires o el castellano italianizado denominado cocoliche que hablan los emigrantes de ese país europeo en Argentina, la coa de ciertas etnias chilenas, el pachuco de la comunidad hispana estadounidense, el lenguaje de la onda

1. Ferdinand de Saussure, Curso de lingüística general, traducción, prólogo y notas de Amado Alonso (Buenos Aires: Losada, 1959) 146 y ss.

2. Dante Medina, «Novela límite y límites de la novela», en Algunas técnicas narrativas de la novela latinoamericana (Guadalajara: Editorial Universidad de Guadalajara, 1990) 5.

3. Cfr. el nivel pragmático de la lengua en Charles W. Morris, Signos, lenguaje y conducta (Buenos Aires: Losada, 1963). 
popular entre los jóvenes mexicanos durante la década de 1970, y el cubiche del habla popular cubana.

Por otro lado, en el habla y la escritura operan mecanismos diferentes. Aun en esta última se distinguen dos niveles: la redacción propiamente dicha y la literatura. Hablar y escribir no es la misma manifestación, son dos: lo que se oye y lo que se ve.

En Yo el Supremo, de Augusto Roa Bastos, los personajes disertan sobre los diferentes mecanismos de la oralidad y la escritura:

Cuando te dicto, las palabras tienen un sentido; otro cuando las escribes. De modo que hablamos dos lenguas diferentes [...] lo que te pido, mi estimado Panzancho, es que cuando te dicto, no trates de artificializar la naturaleza de los asuntos, sino de naturalizar lo artificioso de las palabras ${ }^{4}$.

Distingamos otra manifestación lingüística más: entre la lengua escrita y la lengua hablada existe una desconocida que se puede inventar 5 .

Esta lengua inventada, lúdica por excelencia, es la que llamamos literatura y que le extrae al signo todo su jugo polisémico con el fin de que el texto, ese tejido de significantes, diga lo que nunca había dicho, porque aun en la reiteración se encuentran nuevas formas de decir ${ }^{6}$.

La artificiosidad de la literatura tampoco corresponde a la espontaneidad del habla, no obstante haya quien afirme, por ejemplo, que la escritura de Rulfo equivale al habla popular de los pueblos sureños del estado de Jalisco. La literatura trabaja "haciéndole trampas a la lengua"7 , sistematizando el habla, pero dándole vida a la redacción.

4. $\quad$ Augusto Roa Bastos, Yo el Supremo, edición de Milagros Ezquerro (Madrid: Cátedra, 1983) 151.

5. Palabras del poeta tapatío Raúl Bañuelos e n la conferencia sobre la distinción entre redactar y escribir, dictada en el Centro de Estudios Literarios de la Universidad de Guadalajara, el 9 de febrero de 1990. Allí mismo, Bañuelos cita a Octavio Paz: "la lengua en redacción es como piedra para hacer una escalera; la lengua en escritura es como piedra para hacer una escultura".

6. Por supuesto, no pretendemos reducir la obra literaria — que es más compleja - a la polisemia; pero sí subrayar su importancia.

7. Roland Barthes, El placer del texto y Lección inaugural de la cátedra de semiología literaria del collège de France (México: Siglo XXI, 1984) 121-122. 
En la serie radiofónica cubana de mediados de nuestro siglo, «La Tremenda Corte» de Cástor Vispo, se aborda el fenómeno lingüístico desde esta manifestación de la lengua denominada literatura, puesto que parte de un guión para radio. Pero también recrea ese lastre de la expresión oral, pues, escrito para la oralidad, los intérpretes se permiten algunas morcillas que aunadas al habla popular cubana, están llenas de cómicos giros.

\section{Los lingüisticidas}

En «La Tremenda Corte» se muestra ese carácter polisémico de la lengua gracias a la manipulación lúdica, lo que hemos llamado "lingüisticidio", parodiando al juez de «La Tremenda Corte», quien siempre califica cada caso con el sufijo "cidio", aunque esto sea una exageración en el uso del discurso penal, pues nunca sucede asesinato alguno. Pero en nuestro caso, "lingüisticidio" sí supone muerte, la muerte de la lengua, pero de una lengua lineal, monosémica que se da en esta serie cubana para erigir la pluralidad semántica que permiten las justificaciones de las estafas que comete el ingenioso Trespatines.

¿Pero quién es el responsable de este aniquilamiento de la mecanicidad lingüística? Algunos culparían a Cástor Vispo, autor de los guiones radiofónicos; otros, a los personajes de la serie. Las declaraciones del novelista francés Gustave Flaubert, al afirmar respecto de su célebre novela, "Madame Bovary c'est moi", vienen a invertir los tradicionales conceptos de autor y personajes, y a fusionar la realidad y la literatura en una dimensión donde fluye sangre por las venas de los personajes y los escritores de carne y huesos sólo existen en las fantasías.

En su ensayo «Los niveles de la realidad en literatura», Italo Calvino habla, entre otras cosas, de un amplio campo de desdoblamiento o multiplicación del sujeto, donde un autor, al inventar al personaje autor de su obra, proyecta una parte de sí mismo que puede scr verdadera o ficticia, pues, 
Escribir supone cada vez la elección de una actitud psicológica, de una relación con el mundo, de una impostación de voz, de un conjunto homogéneo de medios lingüísticos, de datos de la experiencia y de fantasmas de la imaginación: un estilo, en suma. El autor es autor porque tiene un papel, como un actor, y se identifica con una determinada proyección de sí mismo en el momento que escribe ${ }^{8}$.

Y más adelante, el escritor italiano se cuestiona: "¿Qué parte del yo que da forma a los personajes es en realidad un yo al que los personajes han dado forma?"9

Se habla de desdoblamiento en la medida en que la literatura, como un producto social, está en manos de sujetos trasindividuales ${ }^{10}$, o en palabras de Calvino:

...las capas que forman al yo del autor no pertenecen al individuo autor, sino a la cultura colectiva, a la época histórica o a las sedimentaciones profundas de la especie ${ }^{11}$.

De este modo, el autor de «La Tremenda Corte», Cástor Vispo, es sólo un pretexto para que la historia de Trespatines y otras historias como la de este personaje corran por el mundo ${ }^{12}$.

Especulemos sobre la reconstrucción del lingüisticidio: en su afán de curar los quistes a la ortografía, la inflamación a la prosodia, la anemia a la analogía y la infección a la $\operatorname{sintaxis}^{13}$, Vispo (aceptemos

8. Italo Calvino, «Los niveles de la realidad en literatura» (1983) 406.

9. Calvino, 407

10. La noción de "sujeto trasindividual" es un elemento del Estructuralismo Genético que recoge la Sociocrítica (ver Edmond Cros, «Introducción a la sociocrítica», 1 y 2. Káñina, X (1986) y Literatura, ideología y sociedad (versión española de S. García Mouton, Madrid: Gredos, 1986).

11. Ibídem.

12. Paráfrasis de las palabras que Augusto Pérez, personaje de Niebla (1914) de Miguel de Unamuno (1864-1936), dirige al mismo autor de la novela que protagoniza.

13. Este discurso pertenece al juez de «La Tremenda Corte», quien en cada caso se queja de padecer múltiples enfermedades. 
que este sea su apellido) hizo gárgaras de humor, agitó la anquilosada gramática castellana hasta desprenderle la última partícula de polvo y, sin seguir la recomendación usual, puso manos a la pluma y comenzó a formar, borrar y quitar, añadir, deshacer y tornar a hacer — diría Cervantes - los libretos de «La Tremenda Corte» e hizo, desde la muerte de la lengua (pero de una lengua mecánica, como hemos aclarado), cómplices de su crimen a un juez y a su secretario, a una mujer de apellido Nananina, a un gallego de nombre Rudesindo, y a un pícaro conocido como José Candelario Trespatines.

\section{3. «La Tremenda Corte»: el cuerpo del delito}

Los programas de «La Tremenda Corte» entraron al aire en el cuadrante radiofónico de la RHC-Cadena Azul el 7 de enero de 1942, luego se escuchó por la CMQ. Se adaptó al teatro y, después de la Revolución Cubana, a la televisión.

La serie es una parodia de los juzgados correccionales: hay acusadores, acusados, testigos, y un juez y su secretario; a veces, cómplices, abogados, fiscales y policías. Con la excepción del Juez y su Secretario, en ocasiones los personajes suelen cambiar sus papeles respecto de acusadores y acusados. José Candelario Trespatines es la figura central de todos los juicios: ya acusado, ya acusador, ya testigo, ya abogado, es el único responsable de los enredos que se pretenden desanudar en el juzgado. Por lo regular tiene como cómplices a su Mamita o a su novia Cucuza (personajes que nunca comparecen a la corte), y aunque a veces logra involucrar a otros personajes en sus fechorías, el resultado en todo caso es el mismo: Trespatines siempre recibe el castigo del Juez.

La secuencia del programa es lineal: 
$\begin{array}{ccc}\text { Presentación (Problemática) } & \longrightarrow \text { Nudo } & \text { Desenlace } \\ \text { (Caso por juzgar) } & \text { (Cómo se suceden } & \text { (El castigo } \\ \text { los hechos) } & \text { para Trespatines) }\end{array}$

Pero a veces se muestra una sucesión circular:

Problemática

(Hay un culpable anónimo)

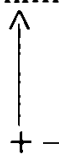

(Presentación)

(Caso por juzgar)

Desenlace

Es decir, el desenlace nos remite de nuevo al principio, o resuelve el enigma planteado al comenzar, por ejemplo, en el caso «Muchachicidio», donde en el día de los inocentes, Trespatines, con sus bromas, le causó lesiones graves a un muchacho. El juicio comienza con la cólera del Juez, porque esa mañana los bomberos, a chorros de agua, lo desalojaron de su casa con el pretexto de haber recibido una llamada en la que se les avisaba que allí había fuego. Hacia el final, Trespatines confiesa sin querer que él fue quien le jugó esa broma a los bomberos.

A pesar de que el radioescucha sabe o intuye el desenlace del juicio, siempre se mantiene el interés hasta que se dicta el fallo contra Trespatines, y ese interés, creemos, lo sostiene la manipulación lúdica de la lengua. Todos los personajes comportan esta actitud respecto del manejo lingüístico, pero sólo mencionaremos algunos casos que corresponden al personaje principal y que están relacionados con los recursos que utiliza Trespatines para justificar sus estafas. Cada uno merece un estudio amplio, aquí solamente los citamos.

a. El uso de palabras que agrupadas de otro modo producen o sugieren un sentido radicalmente distinto (calambur): de jardinero / dejar dinero 
- Trespatines trabaja en una agencia de colocaciones, a la que acude Rudesindo en busca de una plaza de jardinero, pero Trespatines le dice que la única vacante es de albañil y le pregunta si le conviene. El solicitante le contesta que no, que lo que a él le conviene es de jardinero. Trespatines escucha que a Rudecindo le conviene "dejar dinero", entonces piensa que debe empezar por de jar el dinero que trae encima y le roba la cartera («Jardinericidio»).

b. El empleo de palabras de igual ortografía pero diferente significado (homonimia): pie (de imprenta) / pie (parte terminal de cada pierna). Cara (antónimo de barata) / cara (rostro)

- Rudesindo le pidió a Trespatines que lo retratara para la crónica social, y como le advirtió que quería una fotografía económica, es decir, que no le saliera cara, pues lo más importante para él era el impreso al pie, Trespatines sólo le retrató los zapatos («Retraticidio»).

c. El uso de voces de distinta significación pero de igual sonido (homofonía): tubo (pieza hueca, generalmente cilíndrica, más larga que gruesa) / tuvo (forma conjugada del verbo tener, de segunda persona del singular en pretérito de indicativo)

- Trespatines le vendió una cubierta de radio a Rudesindo, quien lo compró convencido de que se trataba de un radio de siete tubos. En realidad Trespatines se refería a siete "tuvos", o sea, que ese radio tuvo antena (1), tuvo alambres (2), tuvo bombillos (3), tuvo amplificador (4), tuvo condensador (5), tuvo onda larga (6) y tuvo onda corta (7) («Españolicidio»).

d. El usode palabras que se diferencian por una letra (paronomasia): nueve / nueva 
- Trespatines está colocado como dependiente en la bodega de Rudesindo; este lo mandó a entregar unos víveres a la señora del nueve y él se los dio a su mamita, porque pensó: "¿quién es la señora del nueve? ¡la nueva!" y la nueva, la que recién se había mudado a esa calle, era su mamita («Bodeguericidio»).

Aquí también se maneja una frase (la señora del...) en dos contextos: (la que vive en... y la mujer de...).

e. Tomar una frase literalmente

- Rudesindo y Nananina piensan ir a Inglaterra a hablar con la Reina Isabel. Rudesindo formó una asociación patriótica llamada «La Reconquista delPeñón de Gibraltar» para exigir la devolución del Peñón y Nananina es Presidenta de la Sociedad Protectora de Monos de Gibraltar, que pide la libertad de los monos. Ambos cambiaron su dinero por moneda inglesa y la guardaron en el establecimiento de Rudesindo. Como Trespatines, que trabajaba ahí como dependiente, había oído decir a Rudesindo que "odiaba todo lo inglés", decidió venderle a su mamita las libras esterlinas a cinco centavos (precio en el que Rudesindo fijó toda la mercancía para arruinar a sus competidores ingleses) («Respetable-comercianticidio»).

* En dos contextos: poner $\$ 20$ (pesos) a Rudesindo (de multa, en el juzgado / en la caja contadora)

- En el calor de la discusión, Trespatines le pide al Secretario que le ponga $\$ 20$ de multa a Rudesindo y el Juez le dice que en el juzgado solamente él tiene ese poder. Trespatines pregunta entonces si podría hacerlo fuera del juzgado y el magistrado le contesta que no le puede poner $\$ 20$ a Rudesindo ni en el 
juzgado ni en ninguna parte, situación que Trespatines confirma para justificar que se quedó con los $\$ 20$ que Rudesindo le pidió que pusiera en la caja, porque "no le puede poner $\$ 20$ a Rudesindo en ninguna parte" («Pañosmenoricidio»).

* Lo dicho en sentido figurado (uso de la sinécdoque): trabajar en las tablas (como actor teatral / como carpintero)

- Trespatines entró a trabajar en la compañía de teatro de don Olegario, porque al contratarlo le aseguró que había trabajado en las tablas. Mientras el contratante pensó en la actuación, el contratado se refería al oficio de carpintero («Teatricidio»).

f. El acomodo de la puntuación en un período para que lo expresado signifique dos cosas a la vez. Generalmente, Trespatines utiliza este recurso en la escritura de sus telegramas:

- Trespatines convenció a Rudesindo para que invirtiera $\$ 100$ en la construcción de un tiovivo cuadrado, con la condición de reembolsárselos cuando el negocio tuviera éxito. Al mes de probar el tiovivo cuadrado en diversos pueblos cubanos, Trespatines le envió a Rudesindo el siguiente telegrama: Aquíme tiene usted giro sus cien pesos volando. Rudesindo leyó que le giraba los $\$ 100$, pero Trespatines quiso decir que quien estaba "giro" (que las burlas no lo dejaban en paz) era él, y que los $\$ 100$ de Rudesindo estaban "volando", porque el negocio había fracasado («Galleguicidio»).

g. La variante sobre un preconstruido (deconstrucción): parar en firme (hacer alto total) en la esquina a ese pollo (jovencita) / parar en firme en la esquina de Toyo (cosmografía cubana).

- Trespatines es guagüero (conductor de ómnibus) y Rudesindo lo acusa de no hacer alto total cuando bajan los pasajeros. 
Rudesindo le pidió "parar en firme en la esquina a ese pollo" y Trespatines aceleró porque entendió "parar en firme en la esquina de Toyo" y todavía faltaba mucho para llegar a ese lugar («Transiticidio»).

\section{Concurrencia intertextual: testigos y defensores}

Sabemos que ningún texto surge de la nada, pues siempre tiene un precedente con el que guarda cierta relación. En «La Tremenda Corte» se reproducen procesos discursivos y se recrean situaciones que son, al mismo tiempo, referencia de otros textos. Vamos a mencionar sólo algunos.

Para empezar, la serie es una parodia de los juzgados correccionales, y este hecho supone ya una copia del discurso jurídico. Muchas veces, este opera a través de la transposición de valores, como en el discurso de Trespatines, quien por ejemplo, suele comenzar su declaración: "cuando yo me robé la máquina pa' dedicarme honradamente al alquiler...". Así pues, hay una fuerte dosis de comicidad en el hecho de proferir una idea en un tono distinto, trastocando el valor moral de una acción.

Otro texto identificable en «La Tremenda Corte», en el nivel de la referencia, es el de la literatura del pícaro, cuyas características podrían resumirse a grandes rasgos de la manera siguiente:

1. Es un personaje de origen desconocido (aunque Trespatines mencione a su mamita, quien muchas veces es la cómplice de sus fechorías, ella es un personaje ausente, que sólo se presenta en el discurso de Trespatines) y de baja extracción social.

2. Sirve a muchos amos (por lo regular Trespatines sirve a Rudesindo, y aquí más que "muchos amos" podríamos hablar de ejercer muchos oficios, pues a pesar de que Rudesindo generalmente es bodeguero, suele cambiar de oficio en cada juicio). 
3. Casi siempre es un personaje maltratado (las "palizas" que recibe el pícaro se traducen en multas y días de encierro para Trespatines).

El barroco español, específicamente el conceptismo y el culteranismo, es otro discurso que aparece deconstruido en «La Tremenda Corte». Por un lado, las asociaciones ingeniosas de ideas o palabras (conceptos) de las que fuera maestro Francisco de Quevedo, y por otro, la expresión refinada de la frase al estilo de Góngora. Para el primer caso, podríamos citar innumerables equívocos, paronomasias, retruécanos, antítesis, paradojas, contrastes, paralelismos, entre otros, que sirvieran de parangón entre «La Tremenda Corte» y cualquier obra satírica quevediana.

Una reproducción del discurso culterano en «La Tremenda Corte» podría ilustrarse con aquel caso en el que Trespatines estafó a Nananina en la venta de un caballo de carreras (efectivamente se trataba de un caballo de Carreras, pero con mayúscula, pues era propiedad de Aniceto Carreras, un carbonero amigo de Trespatines). El animal —convino Nananina - era "una clase de penco que le zumba el güiro", pues estaba más flaco que el mismo Rocinante. El agudo vendedor armó su defensa de la siguiente manera:

...el hecho de que ese cuadrúpedo hípico posea un perfil anatómico de caracteres esqueléticos no es óbice para que se trate de un equino dotado de condiciones estéticas, porque un solípedo puede estar escuálido sin que ello le reste un ápice de belleza a su faz, ni le disminuya una molécula de armonía a su figura estética («Caballicidio»).

Para finalizar, pero no por ello el último, las prácticas discursivas de la vanguardia, en la manifestación dadaísta, también aparecen deconstruidas en «La Tremenda Corte». Recordemos, por ejemplo, la "receta" tzariana para un poema: 
Tomad un diario y unas tijeras. Cortad un trozo de artículo que tenga la extensión prevista para vuestro poema. Recortad cada una de las palabras y metedlas en una bolsa. Removedlas suavemente. Extraed después cada una de las palabras al azar. Copiadlas concienzudamente. El poema se os aparecerá. Y heos aquí un escritor infinitamente original y de una sensibilidad encantadora, aunque incomprendido por el vulgo ${ }^{14}$.

En algunos momentos podemos advertir que Trespatines sigue la "receta" Dadá para armar su discurso:

¡No, no, no, Rudesindo! Legalmente son do' cosa' completamente di'tintas [...] si yo te di con un ladrillo tú no puede' acusarme de que te di con una piedra po'que eso e' tergivelsal la relación ersacta de los hechos encaecido' eh... mejor yo... como dijo... y a lo dijo Napoleón, chico, en la batalla de Llegaipón: "La insuficiencia jurídica de los rinocerontes en bicicleta debe ser orservada de'de el punto de vi' ta legal en una e' trategia filarmónica que tenga la condescendencia, po'que ya dando la facilidá octántica de una excéntrica bien excentricitada" («Rudesindicidio»).

Por otra parte, Dadá se mantuvo fiel al instante: si por cualquier circunstancia un expositor dadaísta era interrumpido, en ese mismo momento daba por terminada la sesión ${ }^{15}$. Trespatines también termina su discurso cuando el Juez interviene. "Las obras maestras dadás no deben durar más de cinco minutos", confesaban sus adeptos. La perorata de Trespatines no se extiende más allá de uno, y todo un juicio de «La Tremenda Corte» le gasta al reloj alrededor dequince minutos.

14. Guillermo de Torre, Historia de las literaturas de Vanguardia, tomo I (Madrid: Guadarrama, 1974) 345 .

15. Al respecto, de Torre (320) cuenta una anécdota de Picabia, quien finalizó la lectura de uno de sus manifiestos cuando alguien llamó a la puerta. 
Una de las principales propuestas dadaístas fue la abstracción absoluta. El absurdo no tardó en extenderse a todas las expresiones artísticas en cuyo recinto las situaciones más inverosímiles encontraron un espacio habitable. Lo mismo sucede en esta serie cubana, donde el absurdo es un signo recurrente. Hablaremos sólo brevemente de ese absurdo que se erige contra lo convencional y lo solemne, y donde lo humorístico y lo patético prodigan la burla, la parodia y la irreverencia. No son sino sarcasmos las tres grandes obras dadaístas que revelan lo iconoclasta de sus miembros: la «Reproducción de la Gioconda» de Marcel Duchamp (donde aparece el retrato de Monna Lisa provisto de regios bigotes) y las obras de Picabia «La Santísima Virgen» (sólo un manchón de tinta) y bajo la reproducción de un mono de terciopelo, los títulos «Retrato de Cézanne», «Retrato de Renoir»y «Retrato de Rembrandt».

En «La Tremenda Corte», Trespatines deconstruye su discurso y llama "El manco del espanto" a Miguel de Cervantes, $\mathrm{y}$ «El bigote de la lancha» a su obra cumbre. Shakespeare es "Chepín", y su personaje Julieta Capuleto, Julieta "Corpulento"; Emilio Zola, Emilio "Suela"; y Jacinto Benavente, Jacinto "Benevolente". La rima XXI de Bécquer es modificada por Trespatines como sigue:

¿Qué es huevo frito? me dices mientras clavas tu mirada en el pálido trasluz.

¿Qué es huevo frito? Y tú me lo preguntas:

¡Huevo frito eres tú! («Incendicidio»)

\section{5. iVenga la sentencia!}

Tal vez la gramática tradicional alojaría a los de «La Tremenda Corte» como huéspedes honorarios no sólo en la famosa prisión cubana, «El príncipe», sino también en las férreas cárceles de San Juan de Ulúa, las Islas Marías, Lecumberry o Alcatraz, si algunas de ellas estuvieran aún en funciones. Pero quizá si creemos — como Ángel, el 
padre del nonato Cristobalito en la novela de Carlos Fuentes-que a la lengua hay que inventarla, porque "se nos muere entre los labios y depende de nosotros resucitarla" ${ }^{16}$, quizá, entonces, les gritaríamos a los lingüisticidas: " $j$ a la reja!", o como dijeran nuestros celadores mexicanos: "¡esos de «La Tremenda Corte», pa'fuera con todo y chivas!"

16. Carlos Fuentes, Cristóbal Nonato (México: Fondo de Cultura Económica, 1987) 27. 